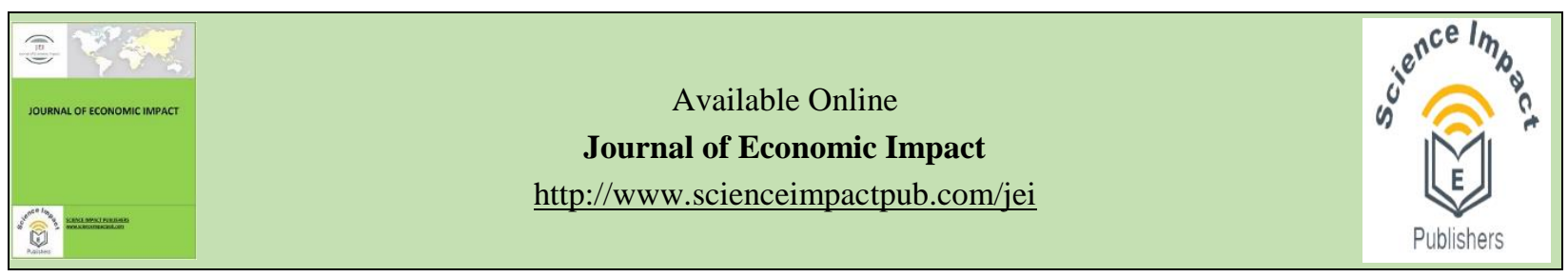

\title{
IMPACT OF FREEDOM OF CHOICE ON INCOME: AN EVIDENCE FROM PAKISTAN
}

\author{
Humaira Mumtaz ${ }^{\mathrm{a}}$, Muhammad Asif Malik ${ }^{\mathrm{b}}$, Haroon Javaid ${ }^{\mathrm{c}}$, Muhammad Asad ur Rehman Naseer ${ }^{\mathrm{d}}$

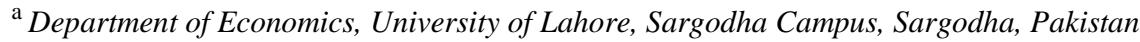 \\ ${ }^{\mathrm{b}}$ Department of Education, University of Lahore, Sargodha Campus, Sargodha, Pakistan \\ ${ }^{c}$ Department of Business Administration, University of Sargodha, Sargodha Pakistan \\ ${ }^{d}$ Institute of Agricultural and Resource Economics, University of Agriculture, Faisalabad, Pakistan
}

\section{HIGHLIGHTS}

- Individual with higher level of perceived decision freedom tend to be more resilient and ultimately finds best ways to increase his income level.

- Study investigated that more choices means more freedom and more freedom means more well-being.

- The study suggested that government should take initial steps to focus on the human psychology to improve the income level at household level.

- $\quad$ People can easily take their decisions independently which will consequently improve the efficiency of social programs and the policies of the government for the poverty reduction.

- Impact of the Social programs aims for poverty reduction can easily be increased by providing education about freedom of speech and freedom of choice at individual level or household level.

\begin{abstract}
People make hundreds of economic decisions each day, from what they will eat or even to decide career move. Research advocates that human behavior is strongly affected by freedom given to him and those blocks avoid them to act in accordance to their interests. The current study under hand is an attempt to explore the impact of freedom of choice on household incomes. Study consumed World Value Survey data for the years 2012-2014 for Pakistan. A simple Linear Regression analysis was used to measure the psychological behaviors on decisions which further affects the income of households in Pakistan ( $=1200$ where Punjab=604, Sindh=278, KPK=168 and Balochistan=150 ). Here Income of an individual is taken as dependent variable and Socio-economic variables (Freedom of choice, Mistrust, Risk aversion, Creativity, Loneliness, Age, Gender, Employment level, No. of children) were taken as independent variables. Study revealed that freedom has a positive impact on income of an individual. It is also concluded by the research that persons with higher level of perceived decision freedom tend to be more resilient and ultimately finds best ways to increase his income level.
\end{abstract}

Keywords: Freedom of choice; level of income; factors of income; Pakistan.

Received: April 17, 2019; Accepted: Aug 23, 2019; Published: Aug 24, 2019.

* Correspondence: Department of Economics, University of Lahore, Sargodha Campus, Sargodha, Pakistan.

Email: humairamumtaz_25@yahoo.com

\section{Introduction}

There are many reasons why one might be interested in human freedom. The concept of freedom of choice has a central place to spend a good quality life is quite old. It was forcefully enlightened by Aristotle. To judge that how much the economic policies are successful, he gave importance to the quality of life the people are living in the society. Economic freedom of choice is important in economic evaluation. As Aristotle noted, "is one undertaken under compulsion, and wealth is evidently not the good we are seeking; for it is merely useful and for the sake of something". We all want to be free. There is nothing as valuable in the life of a man as freedom. If you give the man all the wealth of the world, make a palace of gold for his residence and provide him the best food available in this world but take away his freedom, his life is miserable. There is no happiness in life, if we are dependent on others as Saint Tulsidas had said, "One who is dependent, has no happiness even in his dreams."

We all have some desires like to be become a writer, painter, Prime Minster or President of our country, a film star even we are not free to choose our jobs not free in attaining education of our choice but there are limitations by the rules of the world or the pressure from our parents, society, peer group etc. So we want freedom to become what we wish to be in life. Economic freedom of choice is important in economic evaluation. Some of economic concepts like public welfare, rationality in behavior, 
living standard and human wellbeing can be observed in the context of freedom. We assume that economic freedom of choice promotes human capabilities (Sen, 1985), by giving best options and valuable alternatives to the individuals so that they can better control their lives and ultimately can reduce poverty. Freedom of choice refers to individual's ability to have control on the choice he faces in the life irrespective of its positive or negative outcome if he avail certain choice. In economic sense this refers to choices of the individual to have control in the economic resources to allocate according to his preferences. Sen (1988) expressed that lack of freedom of choice may lead to poverty.

Poverty has turned into an agent word for most analysts and improvement specialists and at times requires no definition. To expect that there is an accord in the comprehension of what poverty implies is anyway wrong. The way that a poor individual in one nation may not be viewed as poor in another nation, or the way that there are family units without income that are not poor, focuses to the distinctions in the comprehension and consequently the meaning of poverty. One of the obstacles to eliminate poverty is political obstacle. This is the responsibility of the state to provide education, credit, clean water, roads, electricity, assets and democratic environment. When the needy and poor got to have all these facilities they can find their way to get out of poverty. It is believe that democracy should be curative to the helplessness of poor in these ways. First, when the elections are fair and free, they can make system to remove corruption and incompetent leaders. The democratic system can provide benefits and incentives to work more efficiently for the public interest. Secondly democracy gave rights to the citizens to express and defend their willingness by the nonelectoral means, through interests groups, social activities, information associations and their NGO's. Poor governance in Pakistan brings constant poverty and responsible for slowing down human development process. Country needs well-built civil society, increase domestic revenue creation, hard and durable economic decisions and has permanent democratic process to attain the effective governance.

Almost every economic decision is based on some risks and uncertainties. People take decisions differently according to their attitudes. Hence many economists explored differences in individual's attitudes in many grounds (Blais and Weber, 2006). Individuals do not always have consistency in risk taking or risk aversion (Schoemaker, 1990). Risk aversion is an individual's attitude in which they negatively respond to uncertainties they are facing i.e. they try to minimize this uncertainty. Risk seeking is an individual's behavior in which he prefer to face the risks. Ben-Ner and Putterman (2001) postulated that "greater risk aversion leads to less trusting". Trust plays an important role in economic decision making. In general Individuals invest their capital in such projects about which they merely know nothing. In this way they reveal trust to certain entity.
Following Coleman trust can be express as an action related to individual putting his resources in the hand of trustee due to his confidence in the trustee.

Economic agents involve in economic transaction not always provide with complete information their trust on willingness of the opposite party and ability of the opposite help them in doing transaction. For instance, a financial advisor cannot be successful without gaining trust of the investors. Following this, Individuals who trust more will be quick in economic decision making and making investment plans than one person who mistrust on economic agents. This may affect the earning of both kinds of individuals. This study tries to empirically investigate this complex relation that who mistrust determine the income of the respondent. Number of individuals committed to breaking down poverty, one of the keenest discussions is over why some poor individuals act in manners that they remain poor. As indicated by Uzonwanne (2016) "through multiple comparisons examining differences in decision making by age and gender analysis showed that almost the same number of males and females used the rational decisionmaking models. Somewhat, age is truly not a causal factor, though. Older adults regularly earn more than young adult. Be that as it may, this isn't such a great amount of due to their age in essence. Rather, it is a direct result of their experience and aptitudes. Having not increased much understanding or numerous abilities, they are not yet as profitable as they could be to a firm. As they develop more seasoned, they profit. Gender bias at work place causes earning gap between female and male. In general female are paid less as compared to male .Therefore females are expected to earn less and males are expected to earn more. .

There are several socio and economic determinants of the level of income. Previous literature more specifically in case of Pakistan ignores freedom of choice of individuals which in turn affect level of income of the individuals. Current study takes into account the ways to increase the freedom of choice. Housofer (2013) also suggested that poverty may have significant emotional price that affect the welfare. This study also included a wide range of economic, demographic and geographic determinants of level of income. The literature on the relationship of economic factors and income is vast however study tries to make an attempt to summarize the maximum literature. Variables obtained from different researches are used in this research. As previous researches based on to find the impact of poverty on different economic variables. Haushofer and Fehr (2014) observed that poverty causes psychological consequences which make people's economic behavior difficult and hence they cannot get out of poverty. They propounded that poverty creates in people stress, meaninglessness and short-sightedness. Man remains in poverty due to its changing irrational behaviors.

Grable (2000) investigated the queries concerning risk taking attitude in ordinary business of life by observing behavioral, demographic and social features. 
He observed that risk acceptance was linked with being married, elder, being male, employment with sophisticated income, further education, higher financial expectations. Outcomes suggested that financial achievement is depend upon one's behavioral characteristics and social and economic background. Akhtar et al. (2017) investigated the main inducing aspects of poverty. Data were collected from Pakistan and used Johansen co-integration technique to find the results. Study used foreign direct investment to GDP, primary education, proportion of agriculture to GDP and military spending are some of the macroeconomic variables. Results showed that these macroeconomic variables have significant and impact on poverty and authors also suggested that these factors can help in making policies for the reduction of poverty.

Hundley (2000) hypothesized that there exist gender income differences in case of self-employment. For panel study data were collected from National Longitudinal Study for High School Class for the year 1972. The analysis showed that the earnings of independent women fell when she got married, increased her family size and the time spend on housekeeping. While the income of self-employed men become greater than before getting married and increased in his family member. The earning of the men and women working in organizations disturbed almost with the same pattern but the earning of self employed women was more sensitive. Ajijola et al. (2011) have studied the relationship between risk behavior and poverty. They have collected data from 120 formers of Ogun state which were chosen randomly. A multi-stage sampling technique, risk attitude model, Foster Greer Thorbecke and probit model were used for empirical analysis. Results of the study showed that maximum male farmers with average age 23 and 49 years responded and they didn't even insure their farms. About 117 out of 120 farmers had risk aversion attitudes. They also concluded that poverty and risk aversion do not have direct relation.

\section{Methodology}

The study explores behavioral characteristics of individual that determine level of income. This study utilized Wave 6 of World Value Survey data. Wave 6 ranges from 2010 to 2014. Data for Pakistan is available for 2012 that is used in this study. This data is collected from 1200 individuals from the four provinces of Pakistan which is reported in table.

$$
\begin{aligned}
& Y_{i}=\alpha_{0}+\alpha_{1} R A_{i}+\alpha_{2} D_{i}+\alpha_{3} E m_{i}+ \\
& \alpha_{4} L F O C_{i}+\alpha_{5} M_{i}+\alpha_{6} \mathrm{~A}_{i}+\alpha_{7} \mathrm{G}_{i}+\alpha_{8} \mathrm{C}_{i}+ \\
& \epsilon_{i} \\
& \text { Where: } \\
& Y_{i} \quad=\text { Leveloficome } \\
& R A_{i}=\text { Risk Aversion } \\
& D_{i} \quad=\text { Democracy } \\
& E m_{i}=\text { Employment } \\
& L_{F O C_{i}}=\text { freedom of choice } \\
& M_{i} \quad=\text { Mistrust }
\end{aligned}
$$

$$
\begin{aligned}
\mathrm{A}_{i} & =\text { Age } \\
G_{i} & =\text { Gender } \\
\mathrm{C}_{i}= & \text { No. of children }
\end{aligned}
$$

Dependent variable: Income is used as dependent variable in the current study under hand. To evaluate level of income of the respondents this study utilized question of WV6 for Pakistan that asks individuals "We would like to know in what group your household is. Please, Specify the appropriate number, counting all wages, salaries, pensions and other incomes that comes in." to choose from 1 to 10 where 1 refers to "Lowest income group in Pakistan" and 10 refers to "Highest income group in Pakistan".

Independent Variables: Freedom of choice refers to individual's ability to have control on the choice he faces in the life irrespective of its positive or negative outcome if he avail certain choice. In economic sense this refers to choices of the individual to have control in the economic resources to allocate according to his preferences. This study utilized question of WV6 for Pakistan that asks individuals "Some people feel they have completely free choice and control over their lives, while other people feel that what they do has no real effect on what happens to them" to choose on likert scale from 1 to 10 where 1 refers to "a great deal of choice" and 10 refers to "no choice". Risk aversion was approximated with the question "Would you please indicate how much this person is like you? Adventure and taking risks are important to this person" to choose on likert scale from 1 to 6 where 1 refers to "Like you" and 6 refers to "Not at all like you". It is almost similar to the questions used by (Haushofer, 2013).

To approximate Democracy the study used the question "How democratically is this country being governed today? Again using a scale from 1 to 10 , where 1 means that it is "not at all democratic" and 10 means that it is "completely democratic," what position would you choose?" To investigate mistrust this study utilized question and individuals were asked to choose on likert scale from 1 to 4 where 1 refers to "I will trust completely the people that I meet for the first time." and 4 refers to "I will not trust at all the people that I meet for the first time."

As the age increases, due to increase in the life experiences the individuals earn more. Question used to find the age of individuals, "How old are you?" and Number of children summarized by the question "Have you had any children?"'

Controlled Variables: In addition to these independent variables, other controlled variables are used in the study. The study used employment dummy in the model where 1 means employed and 0 means unemployed. This study used gender dummy in the estimated model where 1 is assumed for male and 0 is assumed for female.

\section{Results and Discussion}

This chapter presents results and discussion of the study. Several economic factor determined income level, among them freedom of choice plays an important role 
which is included in this model. Moreover, other socioeconomic factors of individuals which are acting as an economic agent also play important role in economic decision making which in turn determine level of income. These economic factors include risk aversion, mistrust which are incorporated in this model. Further, this model also includes few demographic variables which include age; gender and number of children. Results of corresponding regression are shown in table 1 .
It can be seen that the coefficients of almost all variables are other than zero and highly significant.

Freedom of choice has positive association with income level of individuals. It is also significant at 5\% confidence interval with 0.09 value of coefficient. It can be interpreted as if there is one standard deviation increase in freedom of choice of an individual there is 0.09 standard deviation increase in income level.

Table 1: Impact of Freedom of Choice on Income level

\begin{tabular}{|l|c|c|c|c|}
\hline \multicolumn{1}{|c|}{ Variables } & Coef. & Std. Err. & T & P>|t| \\
\hline Risk Aversion & -0.05998 & 0.02837 & -2.11 & 0.035 \\
\hline Democracy & 0.04674 & 0.011202 & 4.17 & 0.000 \\
\hline Employment & 0.2531 & 0.07895 & 3.21 & 0.001 \\
\hline Freedom of choice & 0.09842 & 0.01348 & 7.30 & 0.000 \\
\hline Mistrust & -0.0553 & 0.02805 & -1.97 & 0.049 \\
\hline Age & -0.00014 & 0.00304 & -0.05 & 0.964 \\
\hline Gender & -0.3834 & 0.07659 & -5.01 & 0.000 \\
\hline No. of children & -0.0585 & 0.01737 & -3.37 & 0.001 \\
\hline Constant & -0.7769 & 0.14460 & -5.37 & 0.000 \\
& & & & \\
\hline
\end{tabular}

The study revealed that mistrust and income level have negative relation with each other and significant at $\mathrm{P}<0.05$ with value of coefficient 0.05 . It is interpreted as if there is one standard deviation decrease in mistrust then there is 0.05 standard deviation increase in income level. The study found negative relationship between risk aversion and Income. It can be seen in the table 1 that coefficient of risk averse behavior is 0.05 which is significant at $\mathrm{P}<0.05$. It can be interpreted as if there is 1 standard deviation decrease in risk aversion then there is increase in 0.05 standard deviation of the income. The study also revealed that democracy has positive association with income level. The coefficient for democracy is 0.04 which is significant at $\mathrm{P}<0.05$. It can be interpreted as if there is one standard deviation increase in democracy then there is 0.04 standard deviation increase in income level. Employment intercept dummy is significant at $\mathrm{P}<0.005$. Here assumed reference category is unemployed. Therefore, for employed intercept is $-0.775(-0.78+0.005)$ and for unemployed it is -0.78 . It can be interpreted as keeping all other factor as constant average value of income for employed $(-0.775)$ is more than unemployed $(-0.78)$.

It is revealed that age of the individuals has not significant association with Income Level. It can be seen that coefficient for gender dummy is significant at $\mathrm{P}<$ 0.05 . Here assumed reference category is female. Therefore, for male intercept it is $0.4(-0.78+0.3834)$ and for female intercept is -0.40 . It can be interpreted as keeping all other factor as constant average value of income for female $(-0.78)$ is less than male (0.4).This study found negative relation between number of children and income. It can be seen in the table 1 that coefficient for number of children is 0.059 which is significant at $\mathrm{P}<0.05$. This can be interpreted as if there is 1 unit decrease in number of children then there are 0.059 unit increases in the income.

Risk taking is necessary element in investment decisions. Above results revealed that people who have behavior of taking risk will not eventually increase their incomes. It is well-known that greater the risk greater the reward but a poor person have the lack of potential to replace lost funds. This may lead to low income. Furthermore, above findings reveals that the individuals who mistrust less lies in high income group. They may quicker in taking economic decisions and make investment planning due to trust on economic conditions that will lead to increase in their income. Democracy gave rights to the citizens to express and defend their willingness. Findings reveal that individuals who support democracy lies in high income group. Same as high income group feel lack of freedom of choice this may be due to the fact that they are more rationale. Further, employment status and other demographic variable also contribute in determining income level of individuals.

\section{Conclusion}

Economic freedom of choice promotes human capabilities by giving best options and valuable alternatives to the individuals so that they can better control their lives and ultimately can reduce poverty (Sen, 1985). Study investigated that more choices means more freedom and more freedom means more wellbeing. Results in line with (Çelik et al., 2014; Cornelius \& Averill, 1980; Luthar \& Zigler, 1991; Stockdale et al., 2007) validates " when an individual think that he or she has limited choices and control in their lives they tend to have more chances of anxiety, fear of loss, hopelessness and depression and might not take proper decisions. Conversely if a person has more freedom to take decisions is more likely to have access to resources and 
motivated to seek help and have less aversive actions". Freedom of choice has started to encompass its impact on public policies. This study suggested that government should take initial steps to focus on the human psychology. By doing so, people can easily take their decisions independently which will consequently improve the efficiency of social programs and the policies for the poverty reduction. Social programs aims for poverty reduction can easily be implemented by providing freedom of speech and freedom of choice at individual level. These programs need a little extra expenditures or infrastructure. The success of social programs are only depends on a thoughtful decision making.

\section{References}

Ajijola, S., Egbetokun, O.A., Ogunbayo, I.E., 2011. Impact of risk attitudes on poverty level among rural farmers in Ogun State. Journal of Development and Agricultural Economics, 3(12), 581-587.

Akhtar, R., Liu, H., Ali, A., 2017. Influencing factors of poverty in Pakistan: Time Series Analysis. International Journal of Economics and Financial Issues, 7(2), 215-222.

Ben-Ner, A., Putterman, L., 2001. Trusting and trustworthiness. BUL Rev., 81, 523.

Blais, A.R., Weber, E.U., 2006. A domain-specific risktaking (DOSPERT) scale for adult population. Judgment and Decision making, 1(1). Available at SSRN: https://ssrn.com/abstract=1301089

Çelik A.D., Çetin, F., Tutkun, E., 2014. The role of proximal and distal resilience factors and locus of control in understanding hope, self-esteem, and academic achievement among Turkish preadolescents. Current Psychology, 34(2), 321-345.

Cornelius, R.R., Averill, J.R., 1980. The influence of various types of control on psychological stress reactions. Journal of Research in Personality, 14, 503-517.
Grable, J.E., 2000. Financial risk tolerance and additional factors that affect risk taking in everyday money matters. Journal of Business and Psychology, 14(4), 625-630.

Haushofer, J., 2013. On The psychology of poverty: Evidence from 43 countries. Documento de Trabajo). Disponible en http://web.mit.edu/joha/www.

Haushofer, J., Fehr, E., 2014. On the psychology of poverty. Science, 344(6186), 862-867.

Hundley, G., 2000. Male/female earnings differences in self-employment: The effects of marriage, children, and the household division of labor. ILR Review, 54(1), 95-114.

Luthar, S.S., Zigler, E., 1991. Vulnerability and competence: Review of research on resilience in childhood. American Journal of Orthopsychiatry, 61(1), 6-22.

Schoemaker, P.J., 1990. Are risk-attitudes related across domains and response modes? Management science, 36(12), 1451-1463.

Sen, A., 1985. Well-being, agency and freedom: The Dewey lectures 1984. The Journal of Philosophy, 82(4), 169-221.

Sen, A., 1988. Freedom of choice: concept and content. European Economic Review, 32(2-3), 269294.

Stockdale, S.E., Wells, K.B., Lingqi, T., Belin, T.R., Zhang, L., Sherbourne, C.D., 2007. The importance of social context: Neighborhood stressors, stressbuffering mechanisms, and alcohol, drug, and mental health disorders. Social Science \& Medicine, 65, 1867-1881.

Uzonwanne, F.C., 2016. Influence of age and gender on decision-making models and leadership styles of non-profit executives in Texas, USA. Int. J. Organ Analysis, 24(2):186-203.

\section{Appendix}

Table 2: Summary Statistics for the Impact of Economic Factors on Income Level

\begin{tabular}{|l|c|c|c|c|c|}
\hline Variables & Obs. & Mean & Std. Dev. & Min & Max \\
\hline Risk Aversion & 1200 & $1.41 \mathrm{e}-15$ & 1 & -3.059735 & 1.982053 \\
\hline Democracy & 1200 & 6.519167 & 2.510953 & 1 & 10 \\
\hline Employment & 1200 & 0.3616667 & 0.4806833 & 0 & 1 \\
\hline Lack of Freedom of choice & 1200 & 7.296667 & 2.149614 & 1 & 10 \\
\hline Mistrust & 1200 & $3.02 \mathrm{e}-15$ & 1 & -4.408234 & 1.03776 \\
\hline Age & 1200 & 34.3375 & 11.86441 & 18 & 85 \\
\hline Gender & 1200 & 0.5183333 & 0.4998721 & 0 & 1 \\
\hline No. of children & 1200 & 2.290833 & 2.064736 & 0 & 8 \\
\hline
\end{tabular}


Table 3: Multicollinearity for the Impact of Economic Factors on Income Level

\begin{tabular}{|l|c|c|}
\hline Variables & VIF & 1/VIF \\
\hline Gender & 1.95 & 0.513838 \\
\hline Employment & 1.91 & 0.522938 \\
\hline Age & 1.73 & 0.578778 \\
\hline No. of Children & 1.71 & 0.585481 \\
\hline Lack of Freedom of Choice & 1.12 & 0.896634 \\
\hline Risk Aversion & 1.07 & 0.935989 \\
\hline Democracy & 1.05 & 0.951889 \\
\hline Mistrust & 1.04 & 0.957246 \\
\hline
\end{tabular}

